\title{
Variables affecting sediment sulfide concentrations in regulatory monitoring at salmon farms in the Bay of Fundy, Canada
}

\author{
B. D. Chang*, F. H. Page, R. J. Losier \\ Fisheries and Oceans Canada, St. Andrews Biological Station, 531 Brandy Cove Road, St. Andrews, New Brunswick E5B 2L9,
} Canada

\begin{abstract}
Annual monitoring of sediments is conducted under salmon farms in the southwestern New Brunswick (SWNB) area of the Bay of Fundy, Canada, from August to October. We examined the relationships between the average sediment sulfide concentrations at salmon farms monitored from 2006 to 2009 and some variables related to farm operations: farm age, predicted average near-surface current speed, and estimated biomass of salmon at the time of monitoring. Data for all of these variables were available for $87 \%$ of salmon farms monitored in these years (farms that had been inactive for $>1$ yr were excluded). The year of monitoring had no significant effect, so data from all $4 \mathrm{yr}$ were combined. The ability of the 3 variables to predict sulfide concentrations at the time of monitoring was analyzed using a linear model with log-transformation of variables (except farm age). Each variable individually showed a significant correlation with sulfide concentration, but the model including all 3 variables explained only $37 \%$ of the variation. Current speed and biomass explained the highest proportions of sulfide variation (together $35 \%$ ). Almost $30 \%$ of monitoring events occurred at farms holding no fish. When these fallowed sites were excluded, the model explained only $24 \%$ of sulfide variation, with current speed being the most important predictor variable. Management actions targeted at farm size (biomass) and physical aspects of sites (especially current speed) may help to reduce the risk of causing adverse benthic impacts, but measurable effects may not be observed due to the large amount of sulfide variation that is not explained by these variables.
\end{abstract}

KEY WORDS: Salmon farming · Southwestern New Brunswick · Environmental monitoring Benthic impact · Management

\section{INTRODUCTION}

The growth of salmon farming has led to increasing concerns over the environmental impacts of this industry. To minimize such impacts, regular environmental monitoring of operating farms is conducted in most jurisdictions. Because benthic impacts are easiest to measure, they have been the main focus of most monitoring programs. The most common components of benthic monitoring programs at fish farms are sediment infaunal biodiversity and geochemistry (Wilson et al. 2009).

*Email: blythe.chang@dfo-mpo.gc.ca
Farming of Atlantic salmon Salmo salar in the coastal waters of the Bay of Fundy in southwestern New Brunswick (SWNB), Canada, began in 1978. There are now $>90$ finfish farm leases, although in recent years, only about two-thirds of these leases have been actively growing salmon in any single year. Annual production since 2007 has been 21600 to 26000 t (Statistics Canada 2012).

The regulatory monitoring program for the SWNB salmon farming industry is administered by the New Brunswick Department of Environment \& Local Government (NBDELG). The environmental objective

(C) Fisheries and Oceans Canada 2013. Open Access under Creative Commons by Attribution Licence. Use, distribution and reproduction are unrestricted. Authors and original publication must be credited.

Publisher: Inter-Research · www.int-res.com 
with regard to organic enrichment of sediments is oxic conditions. Since 2006, the environmental indicator for achieving this objective has been sediment sulfide concentration (total $\mathrm{S}^{2-}$, in $\mu \mathrm{M}$ ), with farms rated according to the average sulfide concentration from all monitoring samples (NBDENV 2006; Table 1). The choice of sulfide concentration for the SWNB monitoring program was based on research by Hargrave et al. $(1995,1997)$ and Wildish et al. $(1999$, 2004). The main reasons for choosing this indicator were: scientific confidence in this indicator and sampling methods to describe changes in benthic community structure; repeatability and consistency in sampling and analysis; clear specification of spatial and temporal bounds; and cost effectiveness (NBDENV 2006). Sediment sulfide measurement is also much quicker than infaunal analysis (Brooks \& Mahnken 2003), and hence can facilitate rapid response by regulators and farm operators when poor sediment conditions are detected. Various studies have shown that the diversity of sediment macrofauna under salmon farms declines with increasing sediment sulfide concentrations (Brooks \& Mahnken 2003, Giles 2008, Hargrave et al. 2008, Hargrave 2010), including some research done at salmon farms in SWNB (Wildish et al. 2001a, Chang et al. 2011a). It is, nevertheless, recognized that other indicators may need to be incorporated into the monitoring program (NBDENV 2006). Redox potential (Eh) is also measured (NBDENV 2007), but is not used in the determination of environmental ratings, due to high variability in results; redox can, however, be used for semi-quantitative validation of hypoxic or anoxic results (Wildish et al. 2004).

The purpose of the present study was to examine various environmental and farm management factors, to determine which factors have the strongest influence on benthic environmental quality under salmon farms in SWNB, as measured in the annual regulatory monitoring program. Studies in Norway

Table 1. Environmental ratings based on average sediment sulfide concentration (total $\mathrm{S}^{2-}$ ) in annual monitoring of finfish farms in southwestern New Brunswick. Based on NBDENV (2006)

\begin{tabular}{|lcl|}
$\begin{array}{l}\text { Environmental } \\
\text { rating class }\end{array}$ & $\begin{array}{c}\text { Sediment sulfide } \\
\left.\text { (total } \mathrm{S}^{2-}\right)(\mu \mathrm{M})\end{array}$ & Effects on marine sediments \\
\hline Oxic A & $<750$ & Low effects \\
Oxic B & $750-1500$ & Low effects \\
Hypoxic A & $1500-3000$ & May be causing adverse effects \\
Hypoxic B & $3000-4500$ & Likely causing adverse effects \\
$\begin{array}{l}\text { Hypoxic C } \\
\text { Anoxic }\end{array}$ & $4500-6000$ & Causing adverse effects \\
& $>6000$ & Causing severe damage \\
\hline
\end{tabular}

and Scotland have examined the relationships between benthic environmental conditions under salmon farms and various farm and environmental variables. The most common factors found to influence benthic impacts in those studies have been water circulation, farm biomass, water depth, and/or fallowing (Lumb 1989, Carroll et al. 2003, Mayor et al. 2010). In our study, we wanted to determine whether relationships such as those observed elsewhere occur when using sulfide concentration as the indicator of benthic environmental quality and in the somewhat unique environment in which salmon farming occurs in SWNB.

Salmon farming in Norway and Scotland, as well as in Chile, British Columbia (Canada), and Newfoundland (Canada), usually occurs in deep fjords or lochs with typical fjordic circulation. In SWNB, salmon farming occurs in shallow waters: $85 \%$ of farm leases have average water depths $<20 \mathrm{~m}$ below normal low tide. This is a macro-tidal environment, with a normal tide range of 5.5 to $6.0 \mathrm{~m}$ and a large tide range of 7.7 to $8.1 \mathrm{~m}$ (Canadian Hydrographic Service 2012). The resulting strong tidal currents were considered to be a major benefit for the development of a salmon farming industry in SWNB, because they would prevent waste buildup under farms, except in rare cases (Saunders 1995). The strong tidal circulation, combined with relatively low freshwater input, result in weak stratification: surface salinities in the SWNB farming area usually remain between 25 and 33 psu (Chang et al. 2011b). The salmon farming industry in SWNB is also characterized by a very high density of farms: the entire industry is located within a $60 \times 60 \mathrm{~km}$ area (Fig. 1), and the minimum separation distance between farm leases, according to government regulations, is only $300 \mathrm{~m}$, compared to $1 \mathrm{~km}$ or more in other jurisdictions (Stewart 1998).

We specifically wanted to determine whether the monitoring results are influenced by factors that are considered in SWNB when evaluating potential environmental impacts of new farm proposals and when recommending remedial actions at existing farms. Criteria used to evaluate new farm proposals include the size of the proposed farm, current speeds, and water depths (NBDAFA 2000). At existing farms, remedial actions where poor environmental ratings occur include reduction of biomass (through early harvesting, increasing the fallow period, and/or reducing stocking in the next crop) and repositioning cages to best take advantage of water currents for waste dispersal (NBDENV 2006). 


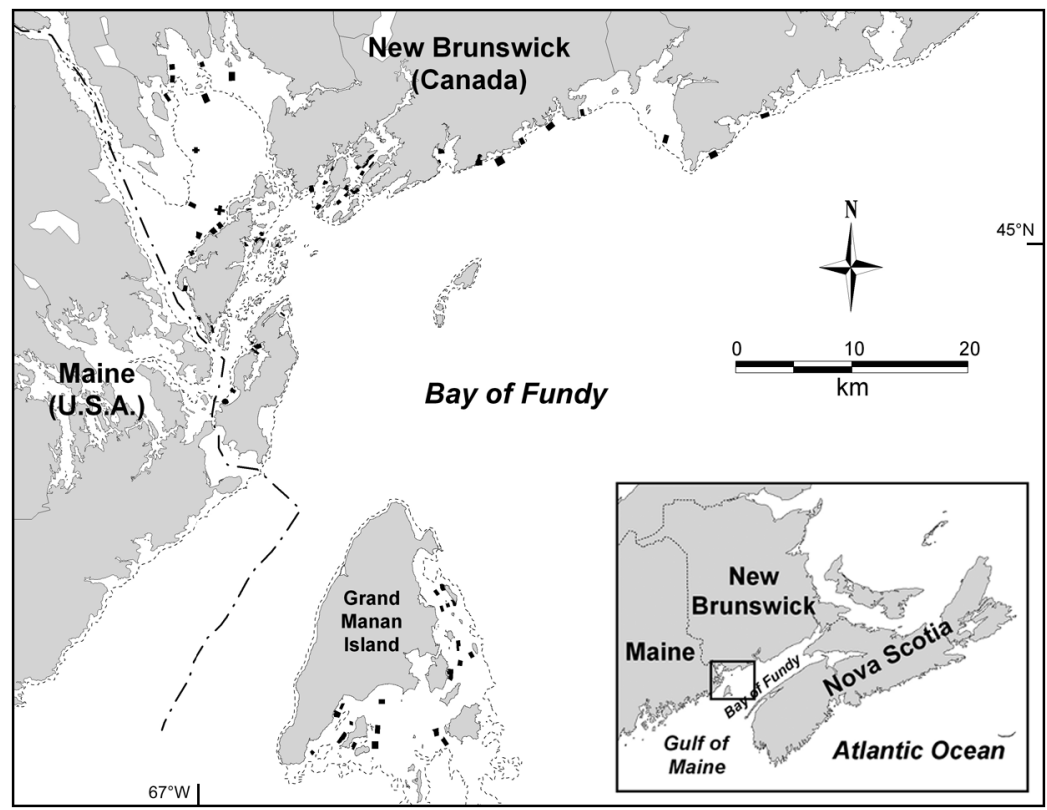

Fig. 1. Map of southwestern New Brunswick (SWNB) showing locations of the 70 salmon farms included in the model. The dashed line along shore indicates the $20 \mathrm{~m}$ depth contour

To achieve the project goals, a linear model was used to examine the relationship between the average sediment sulfide concentration measured in the annual monitoring and selected variables at salmon farms in SWNB. The variables included in the model were: biomass of salmon at the time of monitoring, current speed, and farm age. Water depth and lease area were not included, because a previous study indicated that both of these factors were correlated with farm age and the number of fish stocked (Chang \& Page 2011). The effect of the implementation of fallowing could not be included, because all farms have been required to fallow between successive crops since 2006. However, for monitoring events at fallowed farms, we examined the effect on sulfide concentration of the length of time between the end of harvesting and the date of monitoring.

\section{METHODS}

\section{Study sites}

All farms included in this study were growing Atlantic salmon (Salmo salar). The most commonly used salmon cages in SWNB have circular plastic collars, 70 to $100 \mathrm{~m}$ in circumference (22 to $32 \mathrm{~m}$ diameter), with nets 8 to $12 \mathrm{~m}$ deep, holding 15000 to 35000 fish cage $^{-1}$. The cages are usually arranged in arrays of 1 to 3 rows, with 10 to $20 \mathrm{~m}$ of water separating adja- cent cages. Salmon farms stocked in SWNB between 2006 and 2009 received 60000 to 700000 smolts each (average about 360 000). Since 2006, farms have operated within an Aquaculture Bay Management Area (ABMA) framework (see Chang et al. 2007). Within this framework, farms operate on a 3 yr rotation cycle, each farm must fallow for at least 4 mo between successive crops, and all farms in the same ABMA must fallow for at least 2 simultaneous months. Average water depths (below normal low tide) within farm leases included in the model ranged from 5 to $40 \mathrm{~m}$ (average: $14 \mathrm{~m}$ ).

\section{Sediment sulfide data}

Sediment sulfide data from annual (Tier 1) monitoring from 2006 to 2009 were used in the model. During these years, the monitoring protocols remained constant. Data on other variables (see following subsection) were available for most farms monitored during this period. Details on the monitoring methods from 2006 to 2009 can be found in NBDENV $(2006,2007)$. Monitoring was conducted by environmental consultants, between 1 August and 31 October each year. Sediment samples were collected at 2 cages at farms holding 200000 fish or less, plus an additional cage for every 100000 fish (or part thereof) above 200000 fish. The cages sampled were selected based on fish biomass (the highest biomass cages were given priority), the cage array layout, water current patterns, and the direction of the shoreline. Due to diver safety concerns, only cages located along the perimeter of the cage array were sampled. Three diver-retrieved cores (approximately $30 \mathrm{~cm}$ long $\times 5 \mathrm{~cm}$ diameter) were collected in close proximity (usually within $1 \mathrm{~m}^{2}$, in similar substrates) under the outside edge of each selected cage. The sulfide concentration was measured in 1 sample taken from the top $2 \mathrm{~cm}$ of each core (for a total of 3 measurements per cage sampled) using a silver/sulfide electrode (Wildish et al. 1999, NBDENV 2006). Sampling using surface-deployed grabs was permitted at deeper water sites $(>30.5 \mathrm{~m}$ depth at low tide); however, grabs were utilized in only 2 monitoring events between 2006 and 2009 (both in 2009). At farms that had approvals to operate but were holding no fish at the time of annual monitoring, sediment samples were taken at the same 
locations as the most recent monitoring. Some farms were monitored, even though they had been inactive for $>1 \mathrm{yr}$; these monitoring events were excluded from the model.

Background or reference station data were not collected as part of the monitoring program. Data collected in SWNB away from operating farms and other pollution sources (Hargrave et al. 1995, 1997, Page et al. 2011), and unpublished data (obtained from the New Brunswick Department of Agriculture, Aquaculture \& Fisheries, St. George, New Brunswick) collected since 2000 at new finfish farms prior to the start of operations indicated that reference or background sediment sulfide concentrations in SWNB were consistently $<300 \mu \mathrm{M}$ (Oxic A).

\section{Other variables}

Farm age was defined as the number of years between the current year and the farm's first year of operation (i.e. zero indicates monitoring during a farm's first year of operation); the age was not adjusted for any fallow periods (historical data on fallow periods were not available for most farms). Current meter data were not available at most farms (especially older farms); therefore, to estimate current speeds at all farms, we used a 3-dimensional, finite element circulation model (Greenberg et al. 2005) that was customized for the SWNB area. The circulation model was run using boundary forcing by the principal lunar tide $\left(\mathrm{M}_{2}\right)$ alone; this is the major tidal constituent in SWNB. From this model, we calculated the average predicted current speed (averaged over depth and over 1 tidal cycle, in $\mathrm{cm} \mathrm{s}^{-1}$ ) at the model node nearest to each farm. At all but 3 farms, the nearest node was within the farm lease; in the 3 exceptions, the nearest node was within $20 \mathrm{~m}$ of the lease boundary. Estimates of the biomass (in t) of salmon on site at the time of monitoring were produced by the farm operators. These estimates were usually based on models used by farms to track fish numbers and biomass (adjusted to periodic weight samples, counts, and harvest data).

\section{Data analysis}

The relationships between sulfide concentrations and the selected variables were analyzed using a distance-based linear model: the DistLM routine within PERMANOVA+ for PRIMER 6 software (Anderson et al. 2008). The DistLM routine performs distance- based redundancy analysis, which calculates the probabilities for the relationships between predictor and response variables using permutational (randomization) methods. The response variable was the sediment sulfide concentration, and the predictor variables were: year of sampling, farm age, average predicted current speed, and salmon biomass. Only farms for which data were obtained for all variables were included in the model (the DistLM routine does not allow missing values); data on all variables were obtained for 81 to $94 \%$ of the salmon farms monitored from 2006 to 2009 (farms which had been inactive for $>1$ yr were excluded). To adjust for skewness and kurtosis, $\log _{\mathrm{e}}$ transformations were performed on sulfide concentration, current speed, and salmon biomass. The resemblance matrix for sulfide values among samples was calculated using Euclidean distances. The selection criterion used was adjusted $\mathrm{r}^{2}$. Marginal tests examined the significance and proportion of the sulfide concentration variation explained by individual predictor variables. Sequential tests examined the significance and proportion of the sulfide concentration variation explained by combinations of predictor variables. Tests were run for 9999 permutations. In this study, with 1 response variable and several predictor variables, and using Euclidean distances as the basis of the analysis, the probabilities obtained were equivalent to those obtained from a multiple regression, except there was no assumption that errors would be normally distributed (Anderson et al. 2008).

We also examined the relationship between fish biomass and sediment sulfide concentration at individual farms. Because of the small number of data points per farm in the 2006 to 2009 data (maximum of 4 points farm $^{-1}$ ), we also included data that were available for some farms between 2002 and 2005, although there were slight differences in the monitoring protocols in those years (see Chang \& Page 2011). Spearman's rank correlation coefficient ( $\rho)$ was calculated (McDonald 2009) for the relationship between biomass and sulfide concentration for farms where there were data in at least 4 yr (excluding data at farms which had been inactive for $>1 \mathrm{yr}$ at the time of monitoring).

As indicated above, fallowing was not included in the model. However, for farms holding no fish at the time of monitoring, we examined the effect of the length of the fallow period (i.e. the time in months between the end of harvesting and the date of monitoring) on sulfide concentration, where data were available. The dataset used for this analysis included some monitoring events from 2002 to 2005 (as well as 2006 
to 2009 data). This dataset also included monitoring events at farms that had been fallow for $>1 \mathrm{yr}$.

\section{RESULTS}

\section{Monitoring events included in the study}

A total of 223 monitoring events occurred at 70 different salmon farms between 2006 and 2009 (excluding any monitoring events at farms which had been inactive for $>1 \mathrm{yr}$ ). Most farms (73 to $86 \%$ in any year) received oxic ratings, based on average sediment sulfide concentrations (Table 2). Very few farms (0 to $5 \%$ in any year) received anoxic ratings.

Sixty-three of the 223 monitoring events (28\%) occurred at farms that were fallow (holding no fish) at the time of monitoring: 21 farms in 2006 (34\%), 23 in 2007 (40\%), 14 in 2008 (26\%), and 5 in 2009 (10\%). All but 3 of these 63 monitoring events resulted in oxic ratings, and all but 5 received Oxic A ratings. The monitoring events receiving ratings worse than Oxic A occurred at 5 farms with low average predicted current speeds $\left(<5 \mathrm{~cm} \mathrm{~s}^{-1}\right)$.

There was a total of 195 monitoring events included in the model (i.e. excluding farms which had been inactive for $>1 \mathrm{yr}$ and farms for which any of the predictor variable values were unavailable), representing 70 different farms (Fig. 1). The numbers of farms included per monitoring year were: 54 from 2006, 47 from 2007, 48 from 2008, and 46 from 2009. The farms included in the model represented 81 to $94 \%$ of the salmon farms monitored in each year (excluding farms which had been inactive for $>1 \mathrm{yr}$ ).

\section{Relationships between individual variables and sediment sulfide concentration}

The average sulfide concentration for monitoring events included in the model ranged from 1 to $9468 \mu \mathrm{M}$ (average: $952 \mu \mathrm{M}$ ). Variability among triplicate samples at the same monitoring stations was often high: the standard deviation (SD) per station ranged from $<1$ to $6277 \mu \mathrm{M}$ (mean $=307 \mu \mathrm{M}$ ) and the coefficient of variation $(\mathrm{CV}=[\mathrm{SD} / \mathrm{mean}] \times 100)$ ranged from $<1$ to $173 \%$ (mean $=43 \%)$. The SD for all samples per monitoring event (i.e. all samples taken at the same site on the same date) ranged from $<1$ to 4391 (mean $=552$ ) and the CV ranged from 5 to $240 \%$ (mean $=77 \%$ ).

Farm age ranged from 0 to 29 yr (average $=14$ yr). Predicted average current speed ranged from 1 to
Table 2. Number of salmon farms in southwestern New Brunswick within each environmental rating class from 2006 to 2009. Farms were rated using the average sediment sulfide concentration (total $\mathrm{S}^{2-}$ ) measured during annual monitoring, according to classifications in Table 1. Excludes farms which had been fallow $>12$ mo. Data source: New Brunswick Department of Environment \& Local Government

\begin{tabular}{|lcccc|}
\hline $\begin{array}{l}\text { Environmental } \\
\text { rating class }\end{array}$ & 2006 & 2007 & 2008 & 2009 \\
\hline Oxic A & 36 & 46 & 33 & 28 \\
Oxic B & 9 & 5 & 7 & 9 \\
Hypoxic A & 10 & 4 & 10 & 10 \\
Hypoxic B & 1 & 2 & 2 & 0 \\
Hypoxic C & 3 & 1 & 2 & 0 \\
Anoxic & 3 & 1 & 0 & 1 \\
Totals & 62 & 59 & 54 & 48 \\
\hline
\end{tabular}

$36 \mathrm{~cm} \mathrm{~s}^{-1}$ (average $=9.7 \mathrm{~cm} \mathrm{~s}^{-1}$ ). Fish biomass at the time of monitoring ranged from 0 to $2854 \mathrm{t}$ (average $=$ $416 \mathrm{t})$.

Marginal tests indicated that there was no significant effect of the year of sampling, so data from all years were combined in the model. Marginal tests indicated that there were significant relationships among each of the remaining 3 predictor variables and the average sediment sulfide concentration (Table 3); however, there was considerable scatter in each relationship. The most important variables were biomass and current speed, which each explained $18 \%$ of the sulfide variation (Figs. $2 \& 3$, respectively). Farm age explained $8 \%$ of the sulfide variation (Fig. 4).

The DistLM analysis model using the 3 variables explained $37 \%$ of the average sulfide concentration variation (Table 4). The largest contributions were from current speed and biomass, which together explained $35 \%$ of the sulfide variation.

Farms holding no fish at the time of monitoring had significantly lower sulfide concentrations than

Table 3. Probabilities (p) and proportions (prop.) of variation explained, in marginal tests of individual variables as predictors of the average sediment sulfide concentration $\log _{\mathrm{e}}$ transformed) in annual monitoring at salmon farms, 2006 to 2009. Tests were performed using the DistLM (distancebased linear models) routine within PERMANOVA+ for PRIMER 6 software. Values in bold were significant $(p<0.05)$

\begin{tabular}{|lccc|}
\hline Variables & $\mathrm{n}$ & $\mathrm{p}$ & Prop. \\
\hline Year of monitoring & 195 & 0.10 & 0.03 \\
Farm age & 195 & $\mathbf{0 . 0 0 0 3}$ & 0.08 \\
Log $_{\mathrm{e}}$ (salmon biomass) & 195 & $\mathbf{0 . 0 0 0 1}$ & 0.18 \\
Log $_{\mathrm{e}}$ (average current speed) & 195 & $\mathbf{0 . 0 0 0 1}$ & 0.18 \\
\hline
\end{tabular}




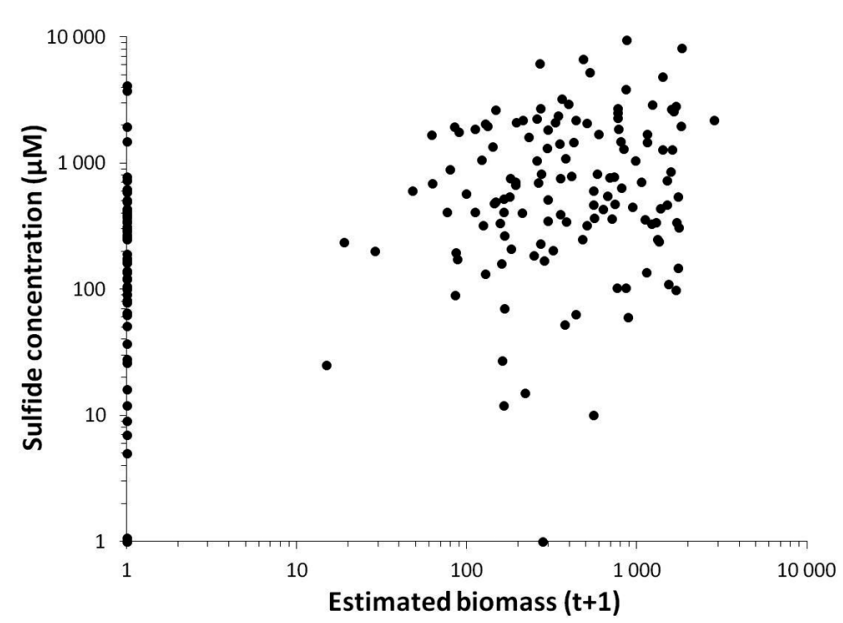

Fig. 2. Log-log relationship between salmon biomass and average sediment sulfide concentration in annual regulatory monitoring at salmon farms in SWNB, 2006 to 2009. Points on $y$-axis are fallowed farms (holding no fish at time of monitoring)

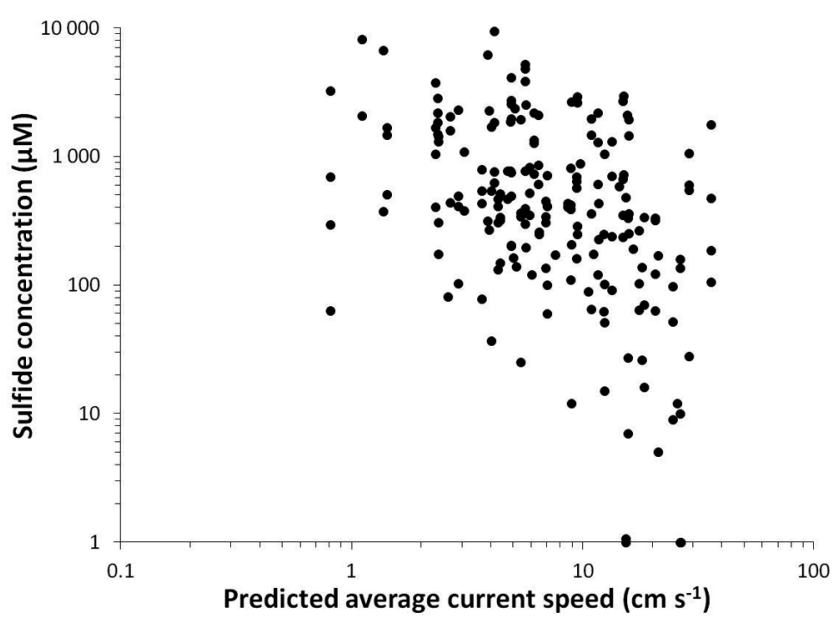

Fig. 3. Log-log relationship between predicted current speed (averaged over depth and over 1 tidal cycle) and average sediment sulfide concentration in annual regulatory monitoring at salmon farms in SWNB, 2006 to 2009

farms with fish (Mann-Whitney $U$-test, $\mathrm{p}<0.001$ ), although there was considerable overlap in values between the 2 groups (Fig. 2). When farms holding no fish at the time of monitoring were excluded from the model, the influence of biomass was reduced to explaining only $3 \%$ of the sulfide variation (but was still significant), while the influence of current speed increased slightly, to explain $19 \%$ of the sulfide variation (Table 5). The model using the 3 variables (excluding farms holding no fish at the time of monitoring) explained $24 \%$ of the sulfide variation (Table 6).

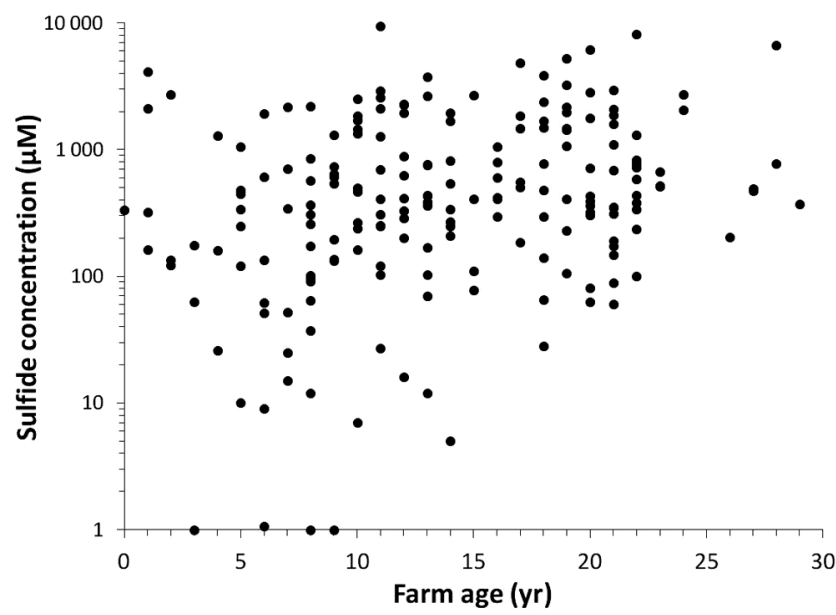

Fig. 4. Semi-log relationship between farm age and average sediment sulfide concentration in annual regulatory monitoring at salmon farms in SWNB, 2006 to 2009

\section{Relationship between fish biomass and sediment sulfide concentration at individual farms}

The relationship between fish biomass and sediment sulfide concentration at individual farms was examined at 45 farms for which there were at least 4 monitoring events from 2002 to 2009 (excluding monitoring events at farms which had been inactive for $>1$ yr). Positive correlations between fish biomass and the average sulfide concentration were observed at 38 of the 45 farms, based on Spearman's rank correlation coefficient $(\rho)$; however, because of the small sample sizes, the correlations were significant $(\mathrm{p}<$ $0.05)$ at only 8 farms.

\section{Relationship between length of fallow period and sediment sulfide concentration}

Of the 137 monitoring events at farms that were fallow at the time of monitoring from 2002 to 2009

Table 4. Probabilities (p) and proportions (prop.) of variation explained, in sequential tests of combinations of variables as predictors of the average sediment sulfide concentration ( $\log _{\mathrm{e}}$ transformed) in annual monitoring at salmon farms, 2006 to 2009. Tests were performed using the DistLM (distancebased linear models) routine within PERMANOVA+ for PRIMER 6 software. Values in bold were significant $(p<0.05)$

\begin{tabular}{|c|c|c|c|}
\hline Variables & $\mathrm{p}$ & Prop. & $\begin{array}{c}\text { Cumulative } \\
\text { prop. }\end{array}$ \\
\hline $\log _{e}($ average current speed) & 0.0001 & 0.18 & 0.18 \\
\hline$+\log _{e}($ salmon biomass) & 0.0001 & 0.17 & 0.35 \\
\hline + Farm age & 0.05 & 0.01 & 0.37 \\
\hline
\end{tabular}


Table 5. As in Table 3, but excluding farms holding no fish at the time of monitoring

\begin{tabular}{|lccc|}
\hline Variables & $\mathrm{n}$ & $\mathrm{p}$ & Prop. \\
\hline Year of monitoring & 132 & 0.50 & 0.02 \\
Farm age & 132 & $\mathbf{0 . 0 0 0 9}$ & 0.08 \\
Loge $_{\mathrm{e}}$ (salmon biomass) & 132 & $\mathbf{0 . 0 3}$ & 0.04 \\
Log $_{\mathrm{e}}$ (average current speed) & 132 & $\mathbf{0 . 0 0 0 1}$ & 0.19 \\
\hline
\end{tabular}

Table 6. As in Table 4, but excluding farms holding no fish at the time of monitoring

\begin{tabular}{|llcc|}
\hline Variables & $\mathrm{p}$ & Prop. & $\begin{array}{c}\text { Cumulative } \\
\text { prop. }\end{array}$ \\
\hline Log $_{\mathrm{e}}$ (average current speed) & $\mathbf{0 . 0 0 0 1}$ & 0.19 & 0.19 \\
+ Log $($ salmon biomass) & $\mathbf{0 . 0 2}$ & 0.03 & 0.22 \\
+ Farm age & 0.08 & 0.02 & 0.24 \\
\hline
\end{tabular}

(including 38 events at farms that had been fallow $>12 \mathrm{mo}$ ), estimates of the time (in months) between the end of harvesting and the date of monitoring were available in 131 cases (representing 79 different farms). Of these 132 cases, there were only 23 monitoring events which received ratings worse than Oxic A (>750 $\mu \mathrm{M}$ average $\left.\mathrm{S}^{2-}\right)$, only 9 were worse than Oxic B (>1500 $\mu \mathrm{M}$ average $\left.\mathrm{S}^{2-}\right)$, and none were worse than Hypoxic B (>4500 $\mu \mathrm{M}$ average $\mathrm{S}^{2-}$ ). All of the non-oxic ratings occurred at farms where the predicted current speeds were below average.

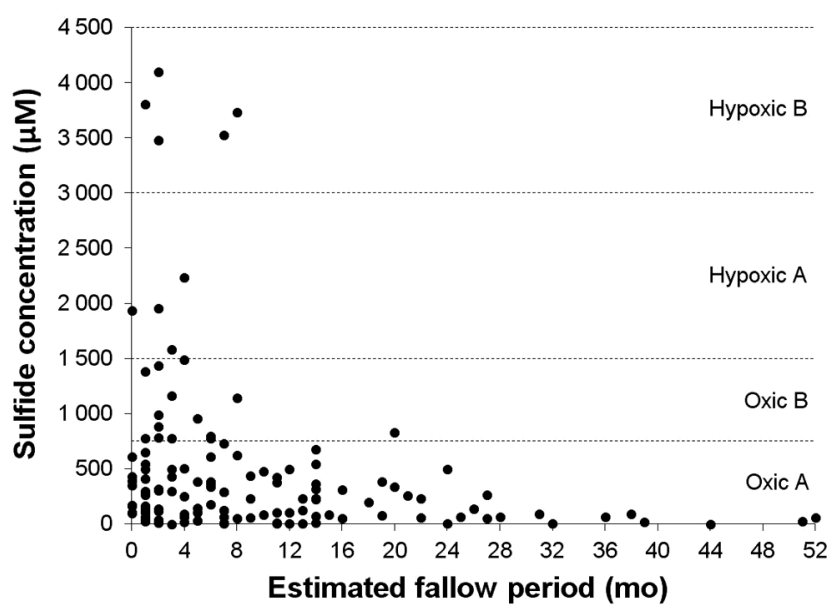

Fig. 5. Relationship between the average sulfide concentration in annual regulatory monitoring at fallowed farms and the length of the fallow period (time between the end of harvesting at the date of monitoring, to the nearest month), 2002 to 2009 . There were 137 monitoring events at farms holding no fish during this period; estimates of the fallow period were available for 131 of these events (including 38 at farms that had been fallow $>12 \mathrm{mo}$ ), representing 79 different farms. A fallow period of 0 mo indicates $<2 \mathrm{wk}$ between harvesting and monitoring
The number of monitoring events (at fallowed sites) with elevated sulfide concentrations decreased as the length of the fallow period increased (Fig. 5). There were 76 monitoring events at farms that had been fallow $>4$ mo. Of these, only 7 received ratings worse than Oxic A (>750 $\mu \mathrm{M}$ average $\mathrm{S}^{2-}$ ) and only 2 were worse than Oxic $B$ $\left(>1500 \mu \mathrm{M}\right.$ average $\mathrm{S}^{2-}$ ).

\section{DISCUSSION}

\section{Relative importance of different factors}

The model including the biomass of farmed salmon, current speed, and farm age explained a significant portion of the variation in sediment sulfide concentration $(37 \%$ of the variation in average sulfide concentration), but almost two-thirds of the variation remained unexplained. The strongest individual predictors of sediment sulfide concentration were the average predicted current speed, which was negatively correlated with sulfide concentration, and the salmon biomass, which had a positive relationship with sulfide concentration; together, these 2 variables accounted for $35 \%$ of the predictive capacity of the model. Farm age was positively correlated with sulfide concentration, but contributed very little to the predictive capacity of the model. When farms holding no fish at the time of monitoring were excluded, the predictive capacity of the model declined to $24 \%$, dominated by the influence of current speed (19\%).

Studies conducted in other salmon farming areas have also looked for relationships between indicators of organic enrichment at salmon farms and various farm variables. In a recent study of Scottish salmon farms, Mayor et al. (2010) found that benthic macrofaunal abundance and sediment organic carbon concentration were influenced by a significant, but weak, interaction between farm size (maximum permitted biomass) and current speed. In addition, the total organic matter concentration in the sediment was influenced by an interaction between distance from the cage and water depth. However, the authors noted that the production and fate of organic waste at fish farms is complex, such that, taken in isolation, current speed, water depth, and farm size were not necessarily good predictors of benthic impacts. In Norway, Carroll et al. (2003) found that environmental classification (based on sediment organic carbon concentration) at salmon farms was not significantly correlated with water depth, farm age, feeding lev- 
els, or average current speed; the only factor they examined which had a significant effect was the implementation of fallowing. An earlier study in Scotland (Lumb 1989) found a relationship between seabed type, water depth, the amount of water movement, and the intensity of organic enrichment. In an analysis of 64 studies on benthic impacts of finfish farms, Giles (2008) found that marine fish farms sited in deep water with high currents had significantly lower environmental impacts than farms in shallow water with low currents.

\section{Effect of current speed}

Higher water currents are expected to flush wastes away from the site, thus decreasing benthic impacts in the immediate vicinity of a farm (Gowan \& Bradbury 1987). In our study, we found a significant negative correlation between the predicted current speed and the sediment sulfide concentration, but this variable alone explained only 18 to $19 \%$ of the variation in sulfide concentration. Because farms in SWNB are mostly in relatively shallow waters, waste materials (feed pellets and feces) will fall quickly to the seafloor. Therefore, only relatively large differences in current speeds will cause significant differences in the distribution of deposited wastes. Nevertheless, the model results suggest that situating farms in locations with higher current speeds can marginally reduce the risk of causing adverse benthic impacts. Other studies have found relationships between current speed and benthic impacts under salmon farms (see Giles 2008). Black et al. (1996) found a negative correlation between the average current speed and the hydrogen sulfide concentration in the water immediately above the seafloor beneath 7 of 8 salmon farms in Scotland and Ireland. Also in Scotland, Lumb (1989) found that the amount of water movement was important in determining organic enrichment under salmon farms. The Norwegian study by Carroll et al. (2003) did not find a significant correlation between current speed and environmental classification (based on organic carbon concentration), although a trend was noted $(p=0.08)$. Higher current speeds may not always reduce the risk of causing benthic impacts. Hall-Spencer et al. (2006) reported significant long-term benthic impacts at high current, shallow salmon farms in Scotland; they observed that wastes would accumulate during slow current periods, and become trapped in maerl beds within seabed depressions.

\section{Effect of fish biomass}

Sediment sulfide concentrations should be related to the amount of organic wastes deposited on the seafloor (Holmer et al. 2005, Hargrave et al. 2008, Hargrave 2010). A higher biomass farm would be expected to produce more waste and, hence, result in higher benthic impacts. However, farm management practices may override this: a high biomass farm with good management practices may produce less waste than a smaller biomass farm with poor management practices. In our model, biomass was positively correlated with sulfide concentration, although the relationship was much weaker when farms holding no fish were excluded. We also found positive correlations between biomass and sulfide concentration at most individual farms in SWNB for which there were sufficient data (i.e. monitoring in at least $4 \mathrm{yr}$ ); however, significant correlations were found at only a few farms, due to the small number of data points per farm.

In British Columbia, Brooks (2001) found that the sediment sulfide concentration showed significant positive correlations with salmon biomass and the amount of feed added at a farm when the biomass and feeding rates were increasing (early in the production cycle), but significant negative correlations at a farm when the biomass and feeding rates were decreasing due to harvesting. He attributed the latter negative correlation to the lag in response of the sediment sulfide concentration to organic matter accumulation. Similar results were found in a study at 2 farms in SWNB (Page et al. 2011): during the first year of the study, while salmon biomass and feeding rates increased during September and October, the average sediment sulfide concentration also increased; but from August to October of the second year, when harvesting was occurring, salmon biomass and feeding rates decreased, while the average sulfide concentration initially increased and then decreased. Our model included monitoring data from farms in all stages of production, from stocking to post-harvest. This may be one reason why the relationship between salmon biomass and sulfide concentration was not stronger.

Another possible reason for the somewhat weak relationship between salmon biomass and sediment sulfide concentration is that stocking rates per cage in SWNB are within a fairly narrow range, regardless of the farm biomass; hence, higher biomass farms have fish spread out among more cages and over a larger area (compared to smaller biomass farms), but the densities of fish per cage do not show a wide variation among farms. Because cages in SWNB are 
usually separated by 10 to $20 \mathrm{~m}$ of water, the overlap in the impacts of adjacent cages is reduced. Therefore, at higher biomass farms, the impacts on sediments may be wider in area, but not necessarily more intense at the most highly impacted locations, except where there is an overlap in impacts from adjacent cages; however, the annual monitoring program is aimed at measuring the intensity of impact, not the area of impact. Nevertheless, the finding of a significant (albeit weak) relationship between fish biomass and the sulfide concentration, and the positive trend between biomass and sulfide concentration observed at most individual farms, suggests that reducing fish biomass should reduce, to a somewhat limited degree, the risk of causing elevated sulfide concentrations under farms where impacts have been observed. However, the weak nature of the relationship means that reducing biomass may not necessarily result in reduced benthic impacts at any individual farm.

\section{Effect of fallowing}

Sulfide concentrations at fallowed farms were mostly oxic and were significantly lower overall than concentrations at farms holding fish. For monitoring events at fallowed farms, we were able to examine the effect on sulfide concentration of the length of time since the beginning of fallowing and the monitoring date. Not surprisingly, the number of fallowed farms with elevated sulfide concentrations decreased with increasing fallow length; 7 of the 9 monitoring events with non-oxic sulfide concentrations were at farms that had been fallow $\geq 4$ mo. Therefore, the mandatory 4 mo fallow period (between successive crops) that is now in place should be sufficient to return sediments to oxic conditions at most farms, but longer fallow periods may be required at some farms, especially where current speeds are low. Studies in other salmon farming areas have found that remediation of sediment geochemistry under farms usually occurs within 6 mo after harvesting (Brooks 2001 and Brooks et al. 2003, in British Columbia; Macleod et al. 2004, 2006, in Tasmania). However, at heavily impacted sites, anoxic sediments can persist up to a year or more after fish have been removed (Lumb 1989, in Scotland; Wildish et al. 2001b, in SWNB; Brooks et al. 2004, in British Columbia). These studies also indicate that biological recovery of the sediments takes considerably more time than geochemical recovery.

Carroll et al. (2003) found that implementation of fallowing was the only significant factor affecting environmental classification at Norwegian salmon farms. We were unable to assess the effect of the implementation of fallowing in our model, because, since 2006, all farms have been required to fallow between crops. We were also unable to assess the effect of the length of fallowing on monitoring results during the next grow-out cycle. This was because the time period between the end of the fallow period and the time of monitoring (during the next grow-out cycle) could be from a few days to years; hence, this variation would likely mask any effect of the length of the fallow period. In Newfoundland, where monitoring must be done near the start and end of the fallow period (Hamoutene et al. 2013), a relationship between the length of the fallow period and benthic impacts measured by the monitoring may be more evident.

\section{Effect of farm age}

In our study, there was a significant, but weak, positive relationship between farm age and sediment sulfide concentration. Another study that included farm age was the Norwegian study by Carroll et al. (2003); however, that study found that farm age was not significantly correlated with environmental classification. In SWNB, the implementation in 2006 of a 3 yr crop rotation system, with mandatory 4 mo fallowing between successive crops, and a performance-based standards approach, should reduce or eliminate the effect of site age, by allowing the seafloor under farms to recover (at least partially) between successive crops. Prior to 2002, very few salmon leases were fallow at the time of monitoring. From 2006 to 2009, 50 to $60 \%$ of the salmon leases were fallow at the time of annual monitoring (including several farms that were fallow and not monitored), and 22 to $26 \%$ were fallow for the entire year.

\section{Other factors}

Some other studies have found an influence of water depth on benthic enrichment. Giles (2008) found that finfish farms in deeper waters generally had lower benthic impacts than those in shallower waters. In Scotland, Lumb (1989) reported that water depth had no influence on the intensity of benthic enrichment at salmon farms located over mud bottom, but, at sandy mud bottom sites, there was a general decrease in benthic enrichment with increasing water depth. In Norway, Carroll et al. (2003) 
found no significant effect of water depth on environmental classification of salmon farms. We did not include water depth in our model, because water depth was found to be correlated with farm age and the number of fish stocked (Chang \& Page 2011). Also, because of the relatively narrow range of water depths among most farms in SWNB, a strong influence of water depth on benthic impacts would not be expected. However, farms at greater water depths (>25 m) usually had low (oxic) sulfide concentrations (Chang \& Page 2011).

Feeding rates have been suggested as another variable which could be used to predict the amount of waste produced and the intensity of environmental impacts (Gowan \& Bradbury 1987, Mente et al. 2006). We did not include feeding rates in our model, because such data were not available on an industrywide basis during our study period. The results of studies by Brooks (2001) and Page et al. (2011) suggest that feeding rates are not always good predictors of sediment sulfide concentrations, especially at farms that have begun to harvest. In another study, Carroll et al. (2003) found that significant correlation between the amount of feed consumed over the previous year and the intensity of environmental impacts at Norwegian salmon farms did not exist. The effect of feeding rates on waste production would be affected by differences in feeds and feeding practices among farms (Mente et al. 2006). Details and difficulties in modeling wastes resulting from feeding at salmon farms have been described by Stucchi et al. (2005).

Feed wastage rates at marine salmon farms appear to have decreased over time, and are now estimated to be usually $5 \%$ or less (Cromey et al. 2002, Brooks \& Mahnken 2003, Black et al. 2008). Chamberlain \& Stucchi (2007) using the DEPOMOD model at a British Columbia salmon farm, predicted that at a feed wastage rate of $5 \%$, waste feed would still account for almost half of the carbon reaching the seafloor, and that at higher feed wastage rates, waste feed would be the dominant contributor of carbon reaching the seafloor. Consultants involved in benthic monitoring at fish farms in SWNB have observed that large amounts of waste feed are often found under farms where highly impacted sediments occur (R. Sweeney, Sweeney International Marine Corp., pers. comm.). This suggests that poor benthic conditions may sometimes be associated with high feed wastage rates. Continuous monitoring of feeding rates, coupled with frequent adjustments to feeding regimes, should be implemented to avoid overfeeding which could lead to adverse benthic conditions.

\section{Uncertainties in data}

Some of the uncertainty in our model may be related to weaknesses inherent in some of the data. Biomass data were estimates provided by farm operators, which in most cases were based on interpolations using farm tracking models. Current speeds were estimated using a circulation model, since actual data were not available for each site, especially for older farms. The circulation model has been validated in many areas, but not at every farm location in SWNB, so model predictions may not be accurate at some sites. Furthermore, the circulation model was run using only the principal tidal constituent in SWNB (the $\mathrm{M}_{2}$ tide); other tidal constituents and wind were not included. Improved circulation models are being developed, which should improve the accuracy of current velocity predictions at farm sites. Another problem, noted by Lumb (1989), is the use of a single velocity measure (such as mean current speed) to characterize a complex hydrological regime.

Another consideration is whether the sulfide concentration data collected by the annual monitoring program accurately represents the benthic conditions at the farm, especially given the small number of sample locations per farm (as few as 2). One factor that could affect variability in sulfide data among sites is that the monitoring was conducted by various consultants. Experience in British Columbia suggests that significant differences in sediment geochemistry data can occur due to small differences in protocols or techniques used by different consultants (Brooks \& Mahnken 2003). However, in the present study and in a previous SWNB study (Chang et al. 2011c), considerable variation in sulfide concentrations was sometimes found among triplicate samples taken from the same monitoring stations, indicating that small-scale spatial variation can be significant. Furthermore, while sediment sulfide concentration is expected to increase as organic waste deposition increases (Holmer et al. 2005, Hargrave et al. 2008, Hargrave 2010), there can be considerable variability in this relationship (e.g. Chamberlain \& Stucchi 2007).

\section{CONCLUSIONS}

As in previous studies in Scotland and Norway (Lumb 1989, Carroll et al. 2003, Mayor et al. 2010), we can conclude that the sediment conditions under salmon farms in SWNB are a result of interactions 
among several factors, and no one variable can be used as a predictor of benthic conditions. Inclusion of all 3 variables in our model explained only about one-third of the variation in sediment sulfide concentration. Nevertheless, our results suggest that holding a large fish biomass, where water current speeds are low, will increase the risk of high sediment sulfide concentrations. Similarly, reducing biomass (and feeding rates) and repositioning cages to take advantage of water currents may help to reduce impacts at farms where high sulfide concentrations have been found, but because biomass and current speed explained relatively small proportions of the total sulfide variability, measurable effects of such actions may not be observed. There are few other management options available for regulators of the industry to deal with farms causing high benthic impacts, other than harvesting fish, fallowing, and restocking at lower levels. Movement of farms to new locations is usually not feasible, because there is a lack of available sites suitable for salmon farming in SWNB.

Much of the unexplained variability may be due to uncertainties in the data for sulfide concentration and the variables included in the model. Also, there may be processes that we have not included in the model, which could explain more of the variation. However, it could also be that much of the scatter may emanate from uncertainty in the actual amount of organic material being released from farms and reaching the seafloor. Spatial and temporal distribution patterns of waste deposition around farms (nearand far-field scales) are affected by site-specific characteristics (cage configurations, bottom topography, sediment resuspension, and farm husbandry practices) that are difficult to characterize in generic waste dispersion models (e.g. Cromey et al. 2002, Stucchi et al. 2005, Chamberlain \& Stucchi 2007). Hence, from a research perspective, perhaps more effort should be focused on developing methodologies to monitor feed wastage or total organic flux coming from fish farms and conditions controlling how much of this flux actually constitutes a flux to the under-field sediments, since this is the variable that drives the sediment impact dynamics.

Finally, it should be recognized that in the vast majority of farms in SWNB, the under-farm sediment sulfide concentrations indicate a relatively low level of impact. Hence, from regulatory and business perspectives, perhaps cost-benefit analyses would be worth exploring, to help determine how much effort should be directed toward developing and implementing further organic impact mitigation methods.
Acknowledgements. Funding for this project was provided by the Fisheries \& Oceans Canada (DFO) Aquaculture Collaborative Research \& Development Program (Project MG08-01-008), the Atlantic Canada Fish Farmers Association, and DFO Science. Monitoring data were provided by the New Brunswick Department of Environment \& Local Government (NBDELG). Monitoring was conducted by Sweeney International Marine Corp., Dominator Marine Services Inc., and Silk Stevens Ltd. We thank the following people for their assistance: T. Lyons and A. Bennett (NBDELG); R. Sweeney, A. Daigle, and T. Daggett (Sweeney International Marine Corp.); E. Garnier (Dominator Marine Services Inc.); M. Szemerda and M. Connor (Cooke Aquaculture); G. Brown and H. Streight (Admiral Fish Farms); M. Kesselring (Northern Harvest Sea Farms); E. Parker, G. Cline, and J. A. Smith (DFO); and G. Smith, L. Hutchin, and K. Coombs (New Brunswick Department of Agriculture, Aquaculture \& Fisheries). We also thank 4 anonymous reviewers for their suggestions.

\section{LITERATURE CITED}

Anderson MJ, Gorley RN, Clarke KR (2008) PERMANOVA+ for PRIMER: guide to software and statistical methods. PRIMER-E Ltd., Plymouth

$>$ Black KD, Kiemer MCB, Ezzi IA (1996) The relationships between hydrodynamics, the concentration of hydrogen sulphide produced by polluted sediments and fish health at several marine cage farms in Scotland and Ireland. J Appl Ichthyol 12:15-20

Black KD, Hansen PK, Holmer M (2008) Salmon aquaculture dialogue: working group report on benthic impacts and farm siting. World Wildlife Fund, Washington, DC

Brooks KM (2001) An evaluation of the relationship between salmon farm biomass, organic inputs to sediments, physiochemical changes associated with those inputs and the infaunal response-with emphasis on total sediment sulfides, total volatile solids, and oxidation-reduction potential as surrogate endpoints for biological monitoring. Final Report for the Technical Advisory Group, British Columbia Ministry of Environment, Aquatic Environmental Sciences, Port Townsend, WA

Brooks KM, Mahnken CVW (2003) Interactions of Atlantic salmon in the Pacific northwest environment. II. Organic wastes. Fish Res 62:255-293

Brooks KM, Stierns AR, Mahnken CVW, Blackburn DB (2003) Chemical and biological remediation of the benthos near Atlantic salmon farms. Aquaculture 219: 355-377

Brooks KM, Stierns AR, Backman C (2004) Seven year remediation study at the Carrie Bay Atlantic salmon (Salmo salar) farm in the Broughton Archipelago, British Columbia, Canada. Aquaculture 239:81-123

Canadian Hydrographic Service (2012) Canadian tide and current tables, 2012, Vol 1: Atlantic coast and Bay of Fundy. Fisheries and Oceans Canada, Ottawa, ON

Carroll ML, Cochrane S, Fieler R, Velvin R, White P (2003) Organic enrichment of sediments from salmon farming in Norway: environmental factors, management practices, and monitoring techniques. Aquaculture 226: 165-180

Chamberlain J, Stucchi D (2007) Simulating the effects of parameter uncertainty on waste model predictions of 
marine finfish aquaculture. Aquaculture 272:296-311

Chang BD, Page FH (2011) Analysis of results from the Environmental Management Program Tier 1 monitoring of salmon farms in southwestern New Brunswick, Bay of Fundy: relationships between sediment sulfide concentration and selected parameters. Can Tech Rep Fish Aquat Sci 2936:1-77. Available at www.dfo-mpo.gc.ca/ Library/343737.pdf (accessed May 2013)

Chang BD, Page FH, Losier RJ, Lawton P, Singh R, Greenberg D (2007) Evaluation of Bay Management Area scenarios for the southwestern New Brunswick salmon aquaculture industry: Aquaculture Collaborative Research and Development Program final report. Can Tech Rep Fish Aquat Sci 2722:1-69. Available at www.dfompo.gc.ca/Library/328479.pdf (accessed May 2013)

Chang BD, Cooper JA, Page FH, Losier RJ, McCurdy EP, Reid JCE (2011a) Changes in the benthic macrofaunal community associated with sediment sulfide levels under salmon farms in southwestern New Brunswick, Bay of Fundy. Aquacult Assoc Can Spec Publ 17:21-23

Chang BD, Page FH, Beattie MJ, Hill BWH (2011b) Sea louse abundance on farmed salmon in the southwestern New Brunswick area of the Bay of Fundy. In: Jones S, Beamish R (eds) Salmon lice: an integrated approach to understanding parasite abundance and distribution. Wiley-Blackwell, Chichester, p 83-115

Chang BD, Page FH, Losier RJ, McCurdy EP, MacKeigan KG (2011c) Characterization of the spatial pattern of sulfide concentrations at six salmon farms in southwestern New Brunswick, Bay of Fundy. Can Tech Rep Fish Aquat Sci 2915:1-24. Available at www.dfo-mpo.gc.ca/ Library/342675.pdf (accessed May 2013)

Cromey CJ, Nickell TD, Black KD (2002) DEPOMODmodelling the deposition and biological effects of waste solids from marine cage farms. Aquaculture 214:211-239

Giles H (2008) Using Bayesian networks to examine consistent trends in fish farm benthic impact studies. Aquaculture 274:181-195

Gowan RJ, Bradbury NB (1987) The ecological impact of salmonid farming in coastal waters: a review. Oceanogr Mar Biol Annu Rev 25:563-575

Greenberg DA, Shore JA, Page FH, Dowd M (2005) A finite element circulation model for embayments with drying intertidal areas and its application to the Quoddy Region of the Bay of Fundy. Ocean Model 10:211-231

Hall-Spencer J, White N, Gillespie E, Gillham K, Foggo A (2006) Impact of fish farms on maerl beds in strongly tidal areas. Mar Ecol Prog Ser 326:1-9

Hamoutene D, Mabrouk G, Sheppard L, MacSween C, Coughlan E, Grant C (2013) Validating the use of Beggiatoa sp. and opportunistic polychaete worm comples (OPC) as indicators of benthic habitat condition at finfish aquaculture sites in Newfoundland. Can Tech Rep Fish Aquat Sci 3028

Hargrave BT (2010) Empirical relationships describing benthic impacts of salmon aquaculture. Aquacult Environ Interact 1:33-46

Hargrave BT, Phillips GA, Doucette LI, White KJ, Milligan TG, Wildish DJ, Cranston RE (1995) Biochemical observations to assess benthic impacts of organic enrichment from marine aquaculture in the Western Isles region of the Bay of Fundy, 1994. Can Tech Rep Fish Aquat Sci 2062. Available at www.dfo-mpo.gc.ca/Library/194363. pdf (accessed May 2013)
Hargrave BT, Phillips GA, Doucette LI, White KJ, Milligan TG, Wildish DJ, Cranston RE (1997) Assessing benthic impacts of organic enrichment from marine aquaculture. Water Air Soil Pollut 99:641-650

> Hargrave BT, Holmer M, Newcombe CP (2008) Toward a classification of organic enrichment in marine sediments based on biogeochemical indicators. Mar Pollut Bull 56: 810-824

Holmer M, Wildish D, Hargrave B (2005) Organic enrichment from marine finfish aquaculture and effects on sediment biogeochemical processes. In: Hargrave BT (ed) Environmental effects of marine finfish aquaculture. Handbook of Environmental Chemistry, Vol 5, Part M, Springer-Verlag, Berlin, p 181-206

> Lumb CM (1989) Self-pollution by Scottish salmon farms? Mar Pollut Bull 20:375-379

Macleod CK, Crawford CM, Moltschaniwskyj NA (2004) Assessment of long term change in sediment condition after organic enrichment: defining recovery. Mar Pollut Bull 49:79-88

Macleod CK, Moltschaniwskyj NA, Crawford CM (2006) Evaluation of short-term fallowing as a strategy for the management of recurring organic enrichment under salmon cages. Mar Pollut Bull 52:1458-1466

Mayor DJ, Zuur AF, Solan M, Paton GI, Killham K (2010) Factors affecting benthic impacts at Scottish fish farms. Environ Sci Technol 44:2079-2084

McDonald JH (2009) Handbook of biological statistics, 2nd edn. Sparky House Publishing, Baltimore, MD. Available at http://udel.edu/ mcdonald/HandbookBioStat.pdf (accessed May 2013)

> Mente E, Pierce GJ, Santos MB, Neofitou C (2006) Effect of feed and feeding in the culture of salmonids on the marine aquatic environment: a synthesis for European aquaculture. Aquacult Int 14:499-522

NBDAFA (New Brunswick Department of Agriculture, Fisheries \& Aquaculture) (2000) Bay of Fundy marine aquaculture site allocation application guide. NBDAFA, Fredericton, NB

NBDENV (New Brunswick Department of Environment) (2006) The environmental management program for the marine finfish cage aquaculture industry in New Brunswick, Version 2.0. NBDENV, Fredericton, NB

NBDENV (New Brunswick Department of Environment) (2007) Standard operating practices for the environmental monitoring of the marine finfish cage aquaculture industry in New Brunswick, July 2007. NBDENV, Fredericton, NB

Page FH, Chang BD, Losier RJ, McCurdy EP, Reid JCE, Hanke AR (2011) Temporal variations in sediment sulfide levels under marine salmon farms in southwestern New Brunswick, Bay of Fundy, during the annual environmental monitoring period. Aquacult Assoc Can Spec Publ 17:64-66

Saunders RL (1995) Salmon aquaculture: present status and prospects for the future. In: Boghen AD (ed) Cold-water aquaculture in Atlantic Canada, 2nd edn. Canadian Institute for Research on Regional Development, Université de Moncton, Moncton, NB, p 35-81

Statistics Canada (2012) Aquaculture statistics 2011, Catalogue No. 23-222-X. Statistics Canada, Ottawa, ON. Available at www.statcan.gc.ca/pub/23-222-x/23-222x2011000-eng.pdf (accessed May 2013)

Stewart JE (1998) Sharing the waters: an evaluation of site 
fallowing, year separation and distances between sites for fish health purposes on Atlantic salmon farms. Can Tech Rep Fish Aquat Sci 2218. Available at www.dfompo.gc.ca/Library/227458.pdf

Stucchi D, Sutherland T, Levings C, Higgs D (2005) Nearfield depositional model for salmon aquaculture waste. In: Hargrave BT (ed) Environmental effects of marine finfish aquaculture. Handbook of Environmental Chemistry, Vol 5, Part M, p 157-179

Wildish DJ, Akagi HM, Hamilton N, Hargrave BT (1999) A recommended method for monitoring sediments to detect organic enrichment from mariculture in the Bay of Fundy. Can Tech Rep Fish Aquat Sci 2286:1-31. Available at www.dfo-mpo.gc.ca/Library/238355.pdf (accessed May 2013)

Editorial responsibility: Marianne Holmer, Odense, Denmark
Wildish DJ, Hargrave BT, Pohle G (2001a) Cost-effective monitoring of organic enrichment resulting from salmon mariculture. ICES J Mar Sci 58:469-476

Wildish DJ, Akagi HM, Hamilton N (2001b) Sedimentary changes at a Bay of Fundy salmon farm associated with site fallowing. Bull Aquacult Assoc Can 101:49-56

Wildish DJ, Akagi HM, Hargrave BT, Strain PM (2004) Interlaboratory calibration of redox potential and total sulfide measurements in interfacial marine sediments and the implications for organic enrichment assessment. Can Tech Rep Fish Aquat Sci 2546:1-40. Available at www. dfo-mpo.gc.ca/Library/287113.pdf (accessed May 2013)

Wilson A, Magill S, Black KD (2009) Review of environmental impact assessment and monitoring in salmon aquaculture. FAO Fish Aquacult Tech Pap 527:455-535

Submitted: January 18, 2013; Accepted: May 15, 2013 Proofs received from author(s): June 19, 2013 